\title{
Construction and Implementation of Three Dimension College English Blended Class During Epidemic
}

\author{
Sun Qian ${ }^{1, \mathrm{a}}$ \\ ${ }^{1}$ School of General Education, Xi'an Eurasia University, Xi'an, Shaanxi 710061, China \\ sunqian@eurasia.edu
}

\begin{abstract}
Faced with the 2019-nCoV outbreak, Chinese universities are required to postpone the 2020 spring semester, and meanwhile meet the requirement of "classes suspended but learning continues" policy, which guarantees the continuous learning for students in the form of online teaching. This paper tries to analyze how online technologies work as supplement, transformation and improvement of the learning process by introducing the construction and implementation of three-dimension college English blended class in Xi' an Eurasia University. Online classes are conducted through video communication Zoom, and online English learning cloud system Unipus is adopted in the pre-class, while class and after class learning sessions, meanwhile online education platform TronClass is used to conduct regular class management for teachers and submit assignments for students. On this basis, this study further elaborates effective measurements to enhance the effectiveness of teaching and learning.
\end{abstract}

Keywords: Online technologies; three-dimension framework; English Blended Class

\section{INTRODUCTION}

Recent years have witnessed a growing popularity of blended class. With its first debut in White Paper on American Educational Technology in 2000, blended learning is favored by most teachers around the world. Statistics show that most online courses offered by American colleges and universities use blended teaching; almost 50\% British universities adopt blending teaching and more than $80 \%$ classes in Singapore are carried out through blended learning [1]. By 2016, New Media Consortium pointed out in 2016 EDUCAUSE Horizon Report that the design and application of blended learning will be one of the most important teaching models in the future [2]. In 2015, the Chinese Ministry of Education released College English Curriculum Requirements, emphasizing the need to further promote the integration of information technology and teaching to make full use of the latest information technology in foreign language teaching. Education Informatization 2.0 Action Plan published in 2018 also mentioned that the main task is to continuously promote information technology in education. Additionally, the large-scale epidemic caused by $2019-\mathrm{nCoV}$ accelerated this process. Teachers all choose cybercasting courses as main teaching mode during this spring semester. This article illustrates how English classes in Eurasia University conduct blended learning with three online teaching devices Zoom, Unipus and TronClass, hoping to provide a feasible way to improve the quality of technology-oriented learning experience.

\section{LITERATURE REVIEW}

Blended learning originated in Western education at the end of 1990s. Since then, the concept of blended learning has gone through three stages. At the first stage, The Sloan Union of the United States proposed that blended learning combines face-to-face classroom and digital learning organically [3]. Scholars regard blended teaching as the transition stage between face-to-face teaching and online teaching. After 2007, the concept has been upgraded, experts hold that blended learning exists only when $30 \%$ to $79 \%$ of the teaching content are taught by online teaching. In this period, scholars focus on interaction between teachers and students, students and students, as well as students and resources. Until 2013, with the rapid development of the Internet and information technology, blended teaching is enriched as "teaching environment based on mobile communication equipment, network learning environment and classroom discussion." At this stage, the perspective of research is shifted from technology and teachers to students, emphasizing to create a "studentcentered" learning system that students can truly participate. Recently, researches on blended learning mainly concentrate on two aspects: the teaching patterns of blended learning and the learning effect of blended learning. For the teaching patterns, foreign scholar urinoma Valia introduced skill-driven model, ability-driven model and attitude-drive model. American scholars Willam Parkman and Craig Barnum proposed four stages blending learning models, which includes web-based network transmission, face-toface learning, solutions, and collaborative extended learning [4]. Chinese scholar Yang Fang introduces blended learning based on MOOC and Rain Class [5]. However, all these 
models are only auxiliary tools of traditional offline teaching. For the learning effects, a survey report conducted by US Department of Education shows that online learning, face-to-face learning, and blended learning are equally effective. According to He Kekang, blended learning combines traditional learning methods and advantages of eLearning. It not only gives play to teachers' leading role in guidance, inspiration, monitoring the teaching process, but also fully stimulates students' imitativeness, motivation and creativity as the learning subjects [6]. However, the previous studies on blended learning lack in depth introduction to blended teaching process, teaching implementation process and teaching feedback. This paper presents a primary research on the teaching and learning process based on Zoom, Unipus and TronClass.

\section{CONSTRCUTION OF THREE- DIMENSION COLLEGE ENGLISH BLENDED CLASS}

College English is designed for freshmen (69 classes, 2415 students) and sophomores (71 classes, 2485 students) for the first four semesters in Xi'an Eurasia University. This spring semester, all courses are forced to switch to online classes, including College English because of 2019-nCoV. To provide students with better learning experiences and guarantee learning effects, College English teaching team design blended classes based on Zoom, Unipus and TronClass, which combines research activities, teaching activities and learning activities effectively.

As an easy, reliable cloud platform, Zoom provides users with video and audio conferencing, training rooms, as well as executive offices and classrooms and webinars across mobile, desktop. English teachers in Eurasia Universities choose Zoom as live broadcasting tool. With an easy access, students can enter Zoom class through a fixed ID shared by teachers, then an online live class where students can discuss and respond to their teachers is created.

Unipus is an online learning platform designed by Foreign Language Teaching and Research Press. Currently more than 700 colleges and universities and over 30,000 teachers in China adopt Unipus in English class. With teaching, learning, training, and testing and evaluation functions, Unipus provides efficient, fast and convenient experience for teachers and students. During the epidemic, Unipus offers free e-textbook and supporting resources and exercises to students and teachers. Students can use mobile phones to download U campus (student) APP to have ubiquitous learning and also get timely evaluation and feedback. Teachers can monitor the learning process through $U$ campus (teacher) APP. In this paper, Unipus is used as pre-class learning tool for students in Eurasia University.

TronClass is an online interactive learning management system, supporting courseware sharing, assignment submission, in-class evaluation, online testing. Since 2015, $\mathrm{Xi}$ 'an Eurasia University began to use TronClass. By April 2019, the total accumulated visits of TronClass platform reached more than 150 million times. Teachers upload courseware before class and check the students' learning progress, class attendance, and assignment evaluation as well as course visits.

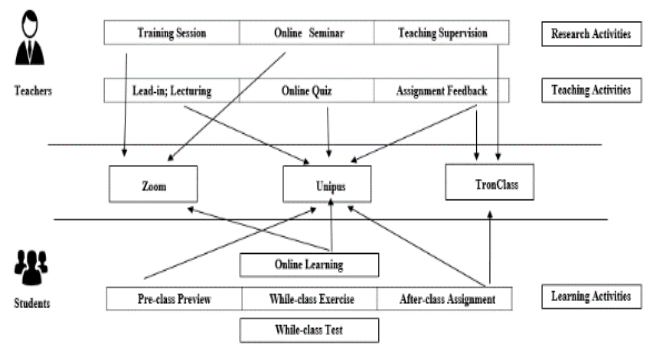

Figure 1 Three Dimension College English Blended Class System

In such a system, teachers have training sessions and efficient online seminars through Zoom. And teaching supervision is conducted through TronClass. Teachers can have learning diagnosis for each individual through checking their learning footprint, learning methods, learning habits and the completion of the learning task. Entering Zoom, students and teachers are having a synchronic class. By sharing screen, students can get a clear view of the PowerPoint. What's more, learners can use the annotation function to mark the language points and learning difficulties. Online video or audio interaction gives students enough chances to have instant communication with teachers. Unipus makes a huge difference during the whole learning process. Usually, students can watch the micro lessons of unit introduction on Unipus as preview. When class begins, Unipus works as the electronic learning material for students. Students can have online quiz or unit test in class and after class. TronClass can be used to submit assignments of all kinds, conduct online chat and peer review.

\section{IMPLEMENTATION OF THREE- DIMENSION COLLEGE ENGLISH BLENDED CLASS}

As a helper and consultant for students to construct meaning, teachers adopt blended learning to guide students to acquire knowledge. A teaching process should contain three stages, namely before class, during class and after class [7]. This thesis will present a detailed learning process consisting of pre-class preparation, while-class participation and after class extension.

\subsection{Pre-class Preparation}

Pre-class Preparation is designed for class lead-in and introduction to learning objectives. Zhang Jin believe that pre-class activities is mainly designed to organize students to help students initially grasp and understand the learning content.

The preparation before class is the basic element in learning 
and it is the important support of the smooth operation of during class and after class activities [8]. When students enter Unipus, they will know the teaching mode set by teachers earlier, which regulates the task deadline. Students can also download learning task through Unipus to get to know the teaching goals, teaching contents and learning requirements. Then by watching the setting the scene video, students will have a brief understanding of the whole unit. Additionally, vocabulary learning and text preview are demanded, and during this period, students can submit their learning difficulties through Unipus, then teachers will adjust the teaching plan accordingly to match the students' existing level and satisfy the learning needs. Good pre-class preparation will help students get ready in advance and make them enter the learning context quickly.

\subsection{While-class Participation}

While-class activities are focusing on pre-test and participative learning. This stage is the core link of knowledge internalization, and it is also the transitional phrase between before class and after class activities.

At first, by using the check-in function of TronClass, teachers can check the class attendance. For the pre-test part, teachers can use the rapid quiz function of Unipus to have online exercise to check students' review situation, further clarifying the teaching focus of this class. Then through Zoom, an online class is conducted. Student-centered activities should be adopted in the process, for example, students are encouraged to give 8 minutes presentation on the latest news, and also other students will give comment on the speakers' performance and the news itself. Sometimes, students will work as a group to present the text analysis they have prepared before class, thus their team work spirit and communication skills will be cultivated gradually. At the end of class, three or four questions will be designed to recheck student online learning conditions. Finally, teachers should organize students to summarize what they have learned during this class and assignments will be given.

\subsection{After class Extension}

After class extension should be conducted based on three principles: consolidating what students have learned at the pre-class and while class stages; assigning online homework; expanding students' existing knowledge.

To consolidate what students have learned, students will finish some fundamental assignments that have been selected by teachers scientifically. What's more, some selfedited exercises can be sent to students to practice consolidate learning; Online homework means learning data can be collected timely, which will help teachers analyze learners behaviors and learners condition; After the basic exercises, extension assignments will be needed. Related reading materials will be sent to students to have critical reading, students will compare opinions with text context and submit a comparative analysis report to present their own ideas. For sophomores, extension CET 4 classes and academic writing on Unipus will be recommended.

\subsection{Learning Feedback}

Jiang Meifen pointed out that when teachers no longer measure student learning with a static score, they will carry out continuous diagnosis of learning, pay attention to the starting point and student engagement, and constantly detect the completion of student learning tasks to identify and respond to the needs of different students. At the same time, the diagnostic information feedback in the learning process also allows teachers to understand the students' grasp of knowledge and help them improve their teaching [13].

English class has developed a learning feedback mechanism based on big data. The mechanism utilizes the smart teaching cloud platform Unipus and TronClass system to form a dynamic feedback mechanism for the entire process based on learning time, learning problems and learning effects.

Learning time feedback refers to the data derived from Unipus, ranking the learning time of whole class even the whole grade. And electric learning badges will be given to those who rank top 10 among the class, at the same time those who rank bottom in the class will receive an advice letter that offers further learning suggestions to motivate them to work harder. Learning problems feedback will be given in assignment grading. Teachers will give a detailed feedback on students homework submitted in TronClass. For the common mistakes students made, teacher will record a video to further explain and instruct students after class. Learning effects feedback means that students' two monthly exam scores will be taken into consideration. Detailed score analysis will be carried by every teacher and further teaching plan and improvement measurements will be submitted to team lead. This learning feedback mechanism will guarantee that students in $\mathrm{Xi}$ 'an Eurasia University could get all-round timely feedback from their English teachers.

\section{CONCLUSION}

With the continuous development of education informatization, the application of blended teaching in various subjects is becoming more and more extensive, and three-dimension college English blended learning model proposed in this study reflects the deep integration of information technology and foreign language teaching. Actually, information technology and foreign language teaching have a natural affinity, and the deep integration of the two injects new vitality to student-centered college English teaching reform and promotes the transformations of teaching and learning behaviors. Online learning effectiveness questionnaire conducted by English Center of Xi'an Eurasia University shows that three-dimension college English blended class can effectively promote 
students' language skills, greatly improve students' participation in teaching activities and interest in learning and finally achieve students' self-quantification and autonomous learning ability.

\section{REFERENCES}

[1] Tan Yingsi. (2019) Literature review on the current research situation of blended learning at home and abroad. J. China Journal of Multimedia \& Network Teaching, 6:4243.

[2] Chen Ming, Lu Xiaoshuang. (2018) An empirical study of College Students' cognition and satisfaction on the curriculum reform of blending teaching model. J. Modern Distance Education, 5:58-65.

[3] Baugher,D.,Vararnelli,A.,et al. (2003) Student hits in an Internet-supported course: How can instructors use them and what do they mean? J. Decision Sciences Journal of Innovative Education, 2:159-179.

[4] Yudko,E.,Hirokawa,et al.(2008) Attitudes, beliefs and attendance hybrid course.J.Computers and Education,4:1217-1227.

[5] Han Chengcai. (2018) Flip classroom and blended learning: the best solution for educational transformation in the Internet era. China Youth Press, Bei Jing.

[6] Yang Fang, Zhang Huanrui, Zhang Wenxia. (2017) A Study on the Blended Learning based on MOOC and Rain Classroom-Taking the Teaching Practice of "Conversational English Skills" MOOC and Rain Classroom as an Example. J. XDIYIS, 5:33-39.

[7] He Kekang. (2004) A View on the new development of educational technology theory from the perspective of blending learning (Part One). J. E-education Research, 3:16.

[8] Wang Zhihong, Zhang Jie. (2020) Construction of Blended Learning in Mosoteach Learning Management System. J. China Educational Technology, 3:100-105.

[9] Zhang Jin, Du Shangrong. (2020) Connotation, value appeal and implementation path of mixed teachin. J. Education and Management, 2:11-13.

[10] Jiang Meifen. (2019) Learning evaluation: the choice of ways to improve the learning quality of college students. J. Heilongjiang Researches on Higher Education. 8: 45-48. 